\title{
Dose-Related Inhibition of Capsaicin Responses by Cannabinoids CBG, CBD, THC and their Combination in Cultured Sensory Neurons
}

\author{
Uma Anand (D) \\ Christian Oldfield' \\ Barbara Pacchetti ${ }^{2}$ \\ Praveen Anand' \\ Mikael H Sodergren ${ }^{1,2}$ \\ 'Faculty of Medicine, Imperial College \\ London, Hammersmith Hospital, London, \\ WI2 ONN, UK; '²MMAC Life Sciences \\ Ltd, London, UK
}

Background: The analgesic effects of Cannabis sativa are mediated by $\Delta^{9}$ tetrahydrocannabinol (THC), but the contributions of other bioactive complex components, including cannabigerol (CBG) and cannabidiol (CBD), are unclear. We describe the individual and combined effects of $\mathrm{CBG}, \mathrm{CBD}$ and $\mathrm{THC}$, on blocking capsaicin responses in dorsal root ganglion (DRG) neurons, in an in vitro model of nociceptor hypersensitivity.

Materials and Methods: Adult rat DRG were dissected and enzyme digested to obtain a neuronal suspension in BSF2 medium containing $2 \%$ fetal calf serum, and the neurotrophic factors NGF and GDNF. After $48 \mathrm{~h}$, cultured neurons were loaded with Fura-2 AM, to determine the effects of cannabinoids on capsaicin responses using calcium imaging. In control experiments, neurons were treated with vehicle, followed by $1 \mu \mathrm{M}$ capsaicin. In cannabinoid treated cultures, CBG, CBD or THC were applied individually, or combined (1:1:1 ratio), followed by $1 \mu \mathrm{M}$ capsaicin. Data from $n=6$ experiments were analysed with Student's $t$-test and Pearson's correlation coefficient.

Results: CBG, CBD and THC, applied individually, elicited dose-related calcium influx in a subset of DRG neurons, and a corresponding dose-related reduction of subsequent responses to capsaicin. Maximum inhibition of capsaicin responses was observed at 30 $\mu \mathrm{M}$ CBG, $100 \mu \mathrm{M}$ CBD, and $100 \mu \mathrm{M}$ THC individually, and with combined CBD $+\mathrm{CBG}$ + THC $(1: 1: 1)$ at $90 \mu \mathrm{M}$. THC $+\mathrm{CBD}+\mathrm{CBG}$ combined in a 1:1:1 proportion has the potential to enhance the potency of these compounds applied individually. There was a high correlation between cannabinoid-mediated calcium influx and reduction of capsaicin responses: $\mathrm{CBG}=-0.88, \mathrm{THC}=-0.97, \mathrm{CBD}=-0.99$ and combined $\mathrm{CBG}+\mathrm{THC}+\mathrm{CBD}=-1.00$.

Conclusion: $\mathrm{CBG}, \mathrm{CBD}$ and THC demonstrated potent dose-related inhibition of capsaicin responses in DRG neurons when applied individually in vitro, and enhanced when applied in combination, being most effective at $90 \mu \mathrm{M}$. Thus, efficacy and tolerability of THC could be improved in combination with $\mathrm{CBG}$ and $\mathrm{CBD}$ at optimal concentrations, which deserve further studies in vivo.

Keywords: cannabinoid, CBG, CBD, THC, TRPV1, DRG neurons, pain

\section{Plain Language Summary}

Chronic pain affects 1 in 15 individuals globally, impacting their quality of life. Current drugs for the treatment of chronic pain have limited efficacy, and undesirable side-effects. The ability of cannabis to provide pain relief is well recognised, as are its many side-effects, which include drowsiness. Cannabis contains hundreds of different compounds, of which tetrahydrocannabinol (THC) is known to be psychoactive, by producing euphoria. Other nonpsychoactive components may also have analgesic effects. Here we have tested the ability of
Correspondence: Uma Anand Faculty of Medicine, Imperial College London, Hammersmith Hospital, Du Cane Road, London, WI2 ONN, UK Email u.anand@imperial.ac.uk 
THC, and the non-psychoactive cannabidiol (CBD) and cannabigerol (CBG) applied individually and in combination, to block responses in pain-sensing neurons, to determine their most effective concentrations for providing pain relief. This was tested in cultured sensory neurons, which are nerve cells grown in a tissue culture dish in a laboratory, and which respond to painful stimuli such as capsaicin (the hot ingredient of chilli peppers). We found that THC, CBG and CBD applied individually were able to block the capsaicin responses in the sensory neurons, and that THC $+\mathrm{CBD}+\mathrm{CBG}$ combined in a 1:1:1 proportion was more effective than these compounds applied alone. This combination also made THC more effective at a lower concentration, with the potential to reduce its unwanted psychoactive effects. The findings of our study will enable the testing of these compounds in human studies, to develop more effective cannabis-based drugs for treating chronic pain, and with reduced side-effects.

\section{Introduction}

Chronic pain may be defined as "pain which has persisted beyond normal tissue healing time", which is generally considered to be three months. ${ }^{1}$ In the UK, $13-50 \%$ of adults are reported to be affected by chronic pain, with $10.4-14.3 \%$ experiencing moderate to severe disabling pain. ${ }^{2}$ The aetiology of chronic pain includes postsurgical pain that affects up to $10 \%$ of patients undergoing surgery, ${ }^{3}$ arthritis and neuropathy, and is influenced by factors such as age, obesity and psychosocial aspects. ${ }^{4}$ Opioids remain a keystone of treatment for severe and persistent pain, in accordance with the analgesic ladder proposed by the World Health Organization (WHO), especially for palliative care. ${ }^{5}$ However, inadequate relief of chronic pain remains an unmet need, severely compromising the quality of life in a significant proportion of affected individuals. The current 'opioid crisis' has accelerated the need for non-opioid treatments of chronic pain.

The identification of the analgesic effects of $\Delta^{9}$ tetrahydrocannabinol (THC), the psychoactive phytocannabinoid derived from the plant Cannabis sativa, ${ }^{6}$ led to the formulation of novel drugs such as Marinol (the synthetic version of Dronabinol), targeting the cannabinoid subtype $1\left(\mathrm{CB}_{1}\right)$ and subtype $2\left(\mathrm{CB}_{2}\right)$ receptors. ${ }^{7}$ Elderly patients with chronic pain treated with Dronabinol reported more than $50 \%$ pain relief in $10 \%$ of patients, and more than $30 \%$ pain relief in $52 \%$ of patients. ${ }^{8}$ However, significant central side-effects of synthetic THC derivatives such as dysphoria have limited their usefulness, ${ }^{9}$ including for chronic neuropathic pain. ${ }^{10,11}$

The analgesic effects of non-psychotropic ingredients of the cannabis plant have been utilized for developing oral medications such as the licensed Sativex (GW Pharmaceuticals, Cambridge, UK), an oromucosal spray containing THC and CBD in a 1:1 ratio, which is more effective and better tolerated. ${ }^{12}$ Cannabinoid combination preparations have provided significant dose-related pain relief for postoperative pain, ${ }^{13}$ and improved pain relief and quality of sleep in patients with chronic neuropathic pain following brachial plexus injury. ${ }^{14}$ A Phase III placebo-controlled study of Sativex also reported alleviation of central neuropathic pain in multiple sclerosis patients. ${ }^{15}$

Cannabis sativa contains hundreds of different components, including 200 different terpenes. These components characterize the complex nature of cannabis, and may provide a variety of therapeutic effects in synergy with cannabinoids. ${ }^{16}$ Recent legalization of medical cannabis supports the development of novel cannabis-based therapeutics, based on emerging information of its less wellknown components. These may have synergistic effects similar to the entourage effect described for endocannabinoids, ${ }^{17}$ via the cannabinoid $\mathrm{CB}_{1}, \mathrm{CB}_{2}$ receptors, and transient receptor potential (TRP) ion channels. While THC is well known to provide pain relief, more information about the non-psychoactive cannabinoid CBD has recently been provided from studies especially in the context of analgesia. ${ }^{18}$

CBD is well known for not being psychoactive or inducing euphoria, ${ }^{7,18}$ - it can increase the tolerability and therapeutic window of THC to potentiate its beneficial effects, ${ }^{19}$ which led to the development of Sativex. Another key nonpsychoactive cannabis component is cannabigerol (CBG), the precursor of $\mathrm{CBD}$ and $\mathrm{THC}$, which modulates cannabinoid receptor subtype $2\left(\mathrm{CB}_{2}\right)$ signalling. ${ }^{20} \mathrm{CBG}$ has more potent analgesic, muscle relaxant, anti-erythema and lipoxygenase blocking activity than THC. ${ }^{12,21,}$

The effects of cannabinoids are mediated by specific cannabinoid receptors, $\mathrm{CB}_{1},{ }^{22}$ and $\mathrm{CB}_{2},{ }^{23}$ to activate downstream effects via adenylyl cyclase inhibition. ${ }^{24}$ There is evidence for CBD and CBG interaction with other receptors such as the transient receptor potential vanilloid subtype 1 receptor (TRPV1) in transfected HEK cells. ${ }^{25-27}$ TRPV1 is expressed in small sensory neurons of the DRG, and which detects noxious stimuli such as temperature of $43^{\circ} \mathrm{C}$ and above, inflammatory mediators, low $\mathrm{pH}$, and capsaicin, the pungent ingredient of chilli peppers. ${ }^{28,29}$ The endocannabinoid anandamide also reduced hyperalgesia and inflammation via peripheral TRPV1 and $\mathrm{CB}_{1}$ receptors expressed in primary afferent fibres. $^{30}$ 
Other members of the TRP ion channel superfamily activated by cannabinoids include TRPA1, which is activated by wasabi and mustard oil, ${ }^{31}$ and is expressed by nociceptors. TRPV1 and TRPA1 are co-expressed in rodent sensory neurons, ${ }^{32}$ increased in human DRG neurons after injury, and cross-desensitize in cultured human and rat DRG neurons. ${ }^{33,34}$ These receptors provide potential targets for the anti-nociceptive effects of cannabinoids. Cannabinoid agonists were previously reported to stimulate TRPV1 and TRPA1 in sensory neurons, leading to calcium influx and desensitization. ${ }^{35}$ We have recently reported CBD inhibition of TRPV1 in DRG neurons at low physiological doses that did not stimulate calcium influx, ${ }^{36}$ similar to inhibition of TRPV1 and TRPM8 in transfected HEK cells. ${ }^{27}$ However, as higher concentrations of cannabinoids induce calcium influx, it is likely that these doses of CBG, CBD and THC would lead to desensitization of TRPV1 in DRG neurons, similar to capsaicin-mediated effects.

In this study, we have used an in vitro model of neuronal hypersensitivity produced by added neurotrophic factors NGF and GDNF, which are increased in clinical chronic pain conditions. ${ }^{37,38}$ Adult DRG neurons cultured with additional neurotrophic factors NGF and GDNF demonstrate neuronal sensitization, manifested as enhanced responses to capsaicin stimuli. ${ }^{33}$ We examined the effects of CBD, CBG and THC on TRPV1 activation by capsaicin in cultured adult rat DRG neurons. Our findings show that these cannabinoids induce dose-related calcium influx and inhibit capsaicin responses when applied individually, with greater inhibition when applied in combination.

\section{Materials and Methods}

\section{Neuronal Cultures}

For each experiment, one adult female Wistar rat (Charles River UK Ltd, Margate, Kent, UK), was sacrificed by exposure to rising titres of $\mathrm{CO}_{2}$ followed by cervical dislocation (with approvals from the Animal Welfare Ethical Review Body, Imperial College London, following UK Home Office approved procedures, and in keeping with the 3Rs ARRIVE guidelines, Animal Scientific Procedures Act (ASPA 1986), in conjunction with guidelines from the Laboratory Animal Science Association (LASA) and Federation of European Laboratory Animal Science Association (FELASA)). Bilateral DRG from all levels were harvested in Ham's F12 medium under sterile conditions, and enzyme digested in $2 \mathrm{~mL}$ Ham's F12 medium containing collagenase $(0.2 \%)$ and dispase $(0.5 \%)$, at $37^{\circ} \mathrm{C}$ for $3 \mathrm{~h}$. The enzyme digested tissue was triturated in $1 \mathrm{~mL} \mathrm{BSF} 2$ medium containing $100 \mathrm{ng} / \mathrm{mL}$ nerve growth factor (NGF-7s, Merck Life Science, UK Ltd), and $50 \mathrm{ng} / \mathrm{mL}$ glial cell-line derived neurotrophic factor (GDNF, Merck Life Science, UK Ltd), trypsin inhibitor and DNase, to obtain a neuronal cell suspension. 8000-10000 neurons in $200 \mu \mathrm{L}$ medium were plated onto each of 20 glass-bottom petri dishes (MatTek Corp, USA), coated with $20 \mu \mathrm{g} / \mathrm{mL}$ poly-1-lysine and $20 \mu \mathrm{g} / \mathrm{mL}$ laminin. The cultures were incubated at $37^{\circ} \mathrm{C}$ for $45 \mathrm{~min}$ to allow the cells to attach before adding $2 \mathrm{~mL}$ BSF2 medium. $24 \mathrm{~h}$ later $5 \mu \mathrm{M}$ cytosine arabinoside was added to all dishes to inhibit the growth of non-neuronal cells. Calcium imaging was performed $48 \mathrm{~h}$ after plating.

\section{Calcium Imaging}

The culture medium was aspirated from each dish, and the neurons rinsed with 4-(2-Hydroxyethyl)piperazine-1-ethanesulfonic acid (HEPES) buffered Hank's Balanced salt solution (HBSS), containing 0.1\% Bovine Serum Albumin (BSA) (pH 7.4). 1 mL HEPES buffered HBSS containing $2 \mu$ Mol Fura-2 AM (Life Technologies, Paisley, UK), was added to each dish, and the petri dishes were incubated at $37^{\circ} \mathrm{C}$ for $40 \mathrm{~min}$. The medium was then replaced with HEPES-HBSS containing $0.1 \%$ BSA for 20 min to allow de-esterification in the dark. The intracellular bound/ unbound $\mathrm{Ca}^{2+}$ ratio was determined by alternately exciting the neurons at 340 and $380 \mathrm{~nm}$ wavelengths $(\lambda \mathrm{ex})$ for one min to establish a stable baseline of the $340 / 380 \mathrm{~nm} \lambda \mathrm{ex}$ ratio. For vehicle control, $0.1 \%$ DMSO was added to the dish, followed $5 \mathrm{~min}$ later by $1 \mu \mathrm{M}$ capsaicin. One image was captured every two seconds in each of three channels: brightfield, $340 \mathrm{~nm}$ and $380 \mathrm{~nm} \lambda \mathrm{ex}$ as previously described. Regions of interest were highlighted in 10-15 phase bright neurons (Figure 1A), and the change of 340/ $380 \mathrm{~nm} \lambda$ ex ratio from baseline to maximum was recorded for each neuron to reveal intracellular $\mathrm{Ca}^{2+}$ changes due to capsaicin or cannabinoid application. In each experiment, the largest calcium responses to the cannabinoid were selected for analysis. Responses were recorded as the difference between baseline (mean 340/380 nm $\lambda$ ex ratio just before addition of the cannabinoid or drug) and peak after the addition. Data were recorded for the mean change in $340 / 380 \mathrm{~nm} \lambda$ ex ratio in response to added cannabinoid (s), and capsaicin, and expressed as a percentage of the control obtained from the same animal specimen. In 
A

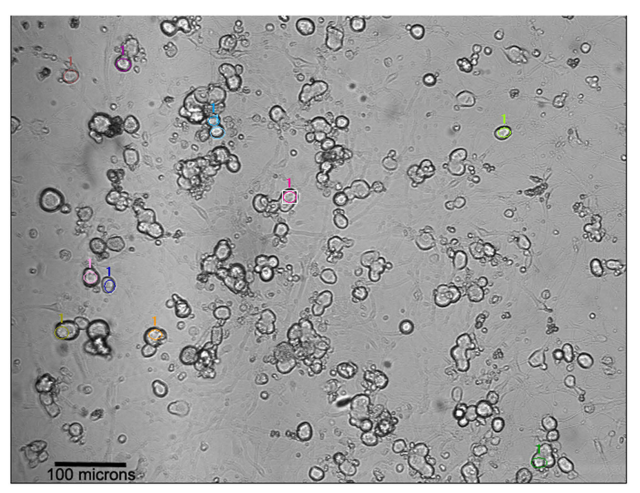

C

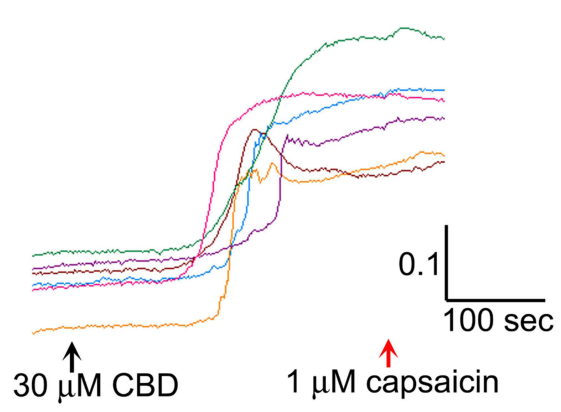

E

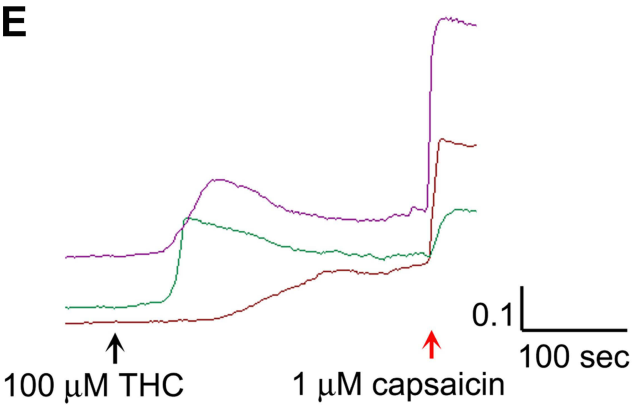

B

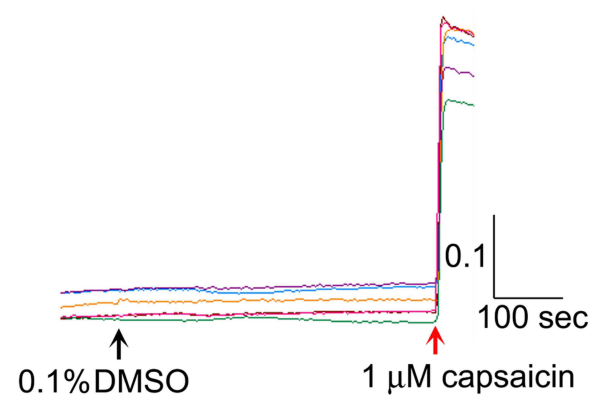

D

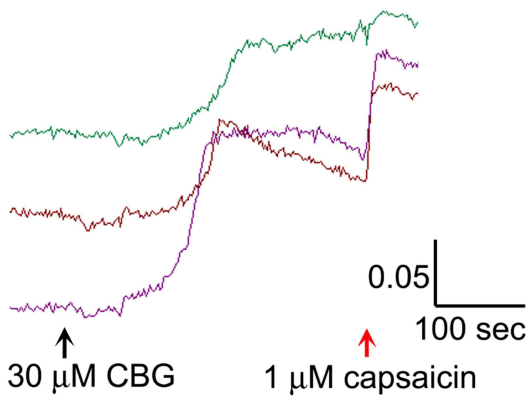

$\mathbf{F}$

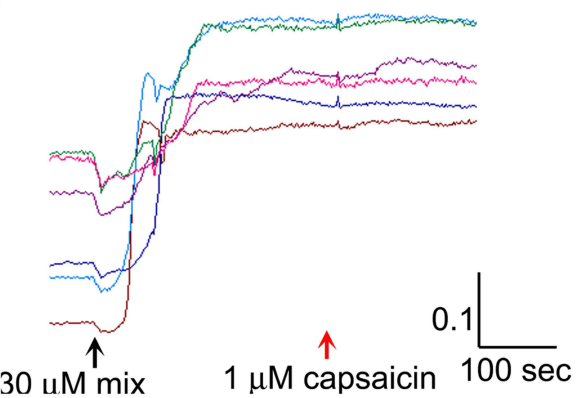

Figure I Image showing a field of view of cultured rat DRG neurons, with individual cells highlighted for analysis; bar=I00 $\mu \mathrm{m}(\mathbf{A})$. Sample traces showing absence of response to vehicle followed by rapid rise in calcium in response to capsaicin (B). Sample traces showing response to $30 \mu M$ CBD followed by I $\mu M$ capsaicin (C). Similar traces of response to $30 \mu \mathrm{M}$ CBG and capsaicin (D). Sample traces of responses to $100 \mu \mathrm{M}$ THC and capsaicin (E). Sample traces of responses to the $30 \mu \mathrm{M}$ mix of CBG + CBD+THC (I:I:I), followed by capsaicin (F). Scale bars indicate change in 340/380 ratio on the $y$ axis, and time in seconds on $x$ axis.

separate dishes, following determination of the baseline, THC $(1,10,30,100,150 \mu \mathrm{M})$, or CBG $(1,10,30,100$ $\mu \mathrm{M})$, CBD $(1,10,30,100 \mu \mathrm{M})$, or combined $\mathrm{CBD} / \mathrm{THC} /$ CBG (1:1:1 ratio, concentrations of 3, 30 or $90 \mu \mathrm{M})$ were added at the indicated concentrations, followed 5 min later by $1 \mu \mathrm{M}$ capsaicin (Figure 1B-F).

\section{Cannabinoid Solutions}

Stock solution of CBG (from extract paste, \#401100P Curaleaf International, London, UK), was prepared at $316 \mathrm{mM}$ in DMSO. $100 \mathrm{mM}$ CBD stock solution was prepared in DMSO (\# 200003, Curaleaf International, London, UK), and
$\Delta^{9}$ THC (\#401100P, Curaleaf International, London, UK) was prepared in DMSO at $317 \mathrm{mM}$. All stock solutions were aliquoted, stored at $-20^{\circ} \mathrm{C}$, and freshly thawed prior to use. Intermediate dilutions were freshly prepared at 1000x final concentration, so that the final concentration of vehicle was $0.1 \%$. THC, CBD and CBG were combined in 1:1:1 proportion by adding each cannabinoid at 1,10 or $30 \mathrm{mM}$ to give a mixture containing 3,30 or $90 \mathrm{mM}$ total in DMSO. This was diluted 1:1000 so that the final concentration of the added mixture was 3, 30 or $90 \mu \mathrm{M}$ for the combination. Capsaicin stock solution was prepared in ethanol as a $100 \mathrm{mM}$ solution, aliquoted and stored at $-20^{\circ} \mathrm{C}$, until use; intermediate dilution 
of $500 \mu \mathrm{M}$ was freshly prepared prior to use. All chemicals were obtained from Merck, unless otherwise indicated.

\section{Data Analysis}

Cannabinoid and capsaicin responses were averaged for each concentration for each rat, and normalized to controls. The number of rats tested for each concentration, and the total number of neurons for each group, from which the data is derived, is indicated in the results Tables below. Average values for each cannabinoid concentration were compared to the control using a one-tailed Student's $t$-test. Pearson's correlation coefficient was used to determine a correlation between calcium influx in response to the cannabinoid, and calcium influx in response to capsaicin administration in the presence of the cannabinoid. All analyses were carried out using GraphPad Prism software. $* \mathrm{P}<0.05, * * \mathrm{P}<0.01, * * * \mathrm{P}<0.001$.

\section{Results \\ Control}

Responses to $1 \mu \mathrm{M}$ capsaicin alone, following vehicle application, were used as control (mean $=100 \pm 20.5 \%$ ). No change in baseline was observed following application of vehicle. Capsaicin responses were observed in phase

A

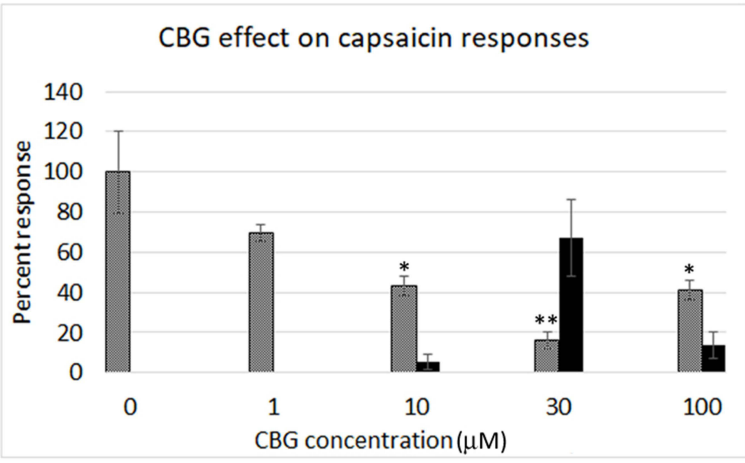

C

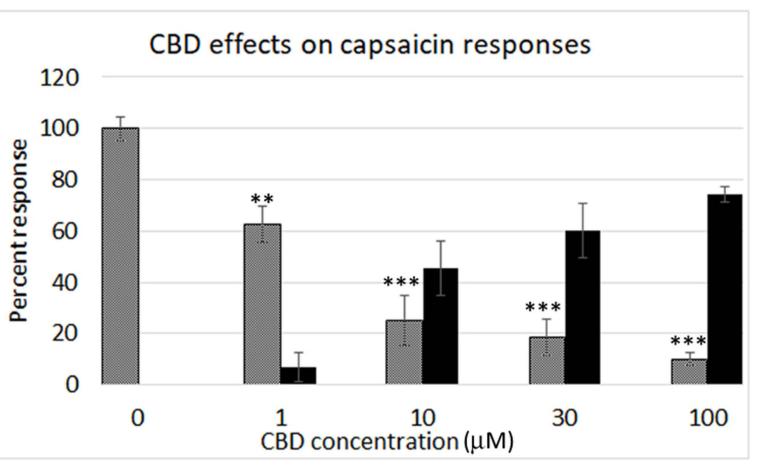

bright neurons (Figure 1A), within seconds of application, as a rapid and sustained increase in intracellular 340/380 ratio (Figure 1B). Application of the cannabinoids resulted in calcium influx after a long delay, unlike the immediate capsaicin responses (Figure $1 \mathrm{C}-\mathrm{F}$ ).

\section{Effect of CBG}

Application of $\mathrm{CBG}$ at $1 \mu \mathrm{M}$ did not elicit calcium influx, but reduced the subsequent capsaicin response (n.s.). Higher concentrations of $10 \mu \mathrm{M}$ and $30 \mu \mathrm{M}$ elicited dose-related increases in calcium influx in a subset of neurons, that was reduced at the highest concentration of $100 \mu \mathrm{M}$ tested, in a bell-shaped distribution. Capsaicin responses showed doserelated reduction, in a U-shaped distribution (Figure 2A). $\mathrm{CBG}$ responses were inversely related to capsaicin response reduction, with a Pearson's coefficient of -0.88 (Table 1 ).

\section{Effect of THC}

Dose-related calcium influx was observed in a subset of neurons, following application of THC at 1, 10, 30, 100 and $150 \mu \mathrm{M}$ in a bell-shaped distribution. Corresponding dose-related reduction of capsaicin responses was observed in the presence of $\mathrm{THC}$, with maximum

B

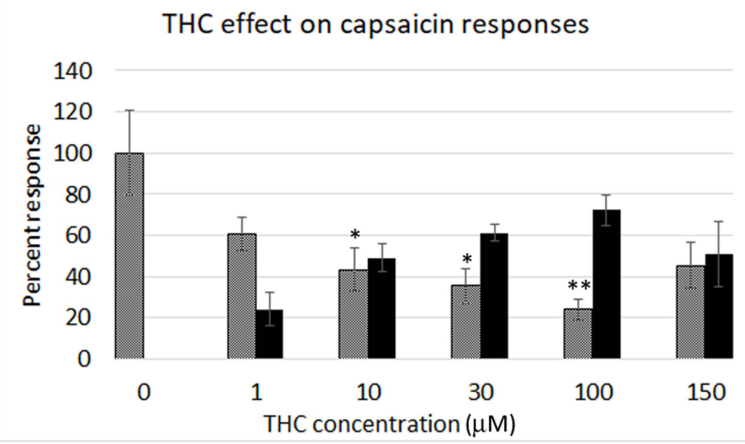

D

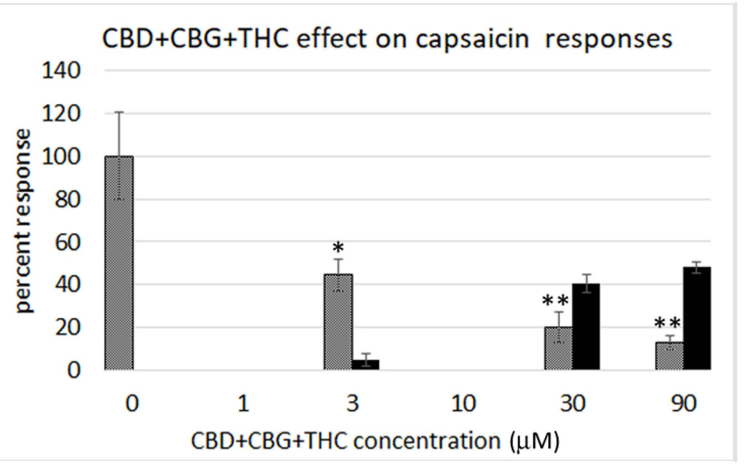

Figure 2 Graphs showing dose-related calcium responses to cannabinoids (black bars), CBG (A), THC (B), CBD (C), and combined CBD+CBG+THC (D). Each graph also shows the inhibitory effects of the added cannabinoids on capsaicin responses (grey bars) at the indicated concentrations, expressed as a percentage of calcium influx in response to I $\mu \mathrm{Mol}$ capsaicin. The inhibition of capsaicin responses was inversely proportional to the cannabinoid concentrations. $* \mathrm{P}<0.05$, $* * \mathrm{P}<0 . \mathrm{I}$, $* * * \mathrm{P}<0.00 \mathrm{I}$. 
Table I Effect of CBG

\begin{tabular}{|l|l|l|l|l|l|}
\hline CBG concentration $(\mu \mathrm{M})$ & 0 & 1 & 10 & 30 & 100 \\
\hline $\begin{array}{l}\text { CBG response } \\
\text { Mean } \pm \text { s.e.m }\end{array}$ & 0 & 0 & $5.3 \pm 4$ & $67.2 \pm 19$ & $13.5 \pm 6.6$ \\
\hline $\mathrm{N}$ (neurons) & $8(52)$ & $6(47)$ & $6(60)$ & $6(58)$ & $6(37)$ \\
\hline Capsaicin response Mean \pm s.e.m. & $100.0 \pm 20.5$ & $69.8 \pm 4.3$ & $43.1 \pm 5.1^{*}$ & $16.0 \pm 4.2^{* *}$ & $41.2 \pm 4.8^{*}$ \\
\hline $\mathrm{N}$ (neurons) & $8(52)$ & $6(47)$ & $6(59)$ & $6(58)$ & $6(44)$ \\
\hline
\end{tabular}

Notes: Data showing dose-related responses to $C B G$ expressed as a percentage of the response to I $\mu$ Mol capsaicin, and reduction of capsaicin responses following CBG application. " $N$ " indicates number of rats tested for each concentration, with the total number of neurons in each group, from which the data is derived, in brackets. *P $<0.05$, $* * \mathrm{P}<0.01$, Students $t$-test.

reduction at $100 \mu \mathrm{M}$, in a U-shaped distribution (Pearson's coefficient $=-0.99$, Table 2, and Figure 2B).

\section{Effect of CBD}

Application of $\mathrm{CBD}$ at $1,10,30$ and $100 \mu \mathrm{M}$ concentrations elicited dose-related calcium influx, with corresponding dose-related reduction of capsaicin responses. Figure $2 \mathrm{C}$ and Table 3.

\section{Effect of Combined CBG, THC and CBD} Combined $\mathrm{CBG}+\mathrm{THC}+\mathrm{CBD}$ applied in a 1:1:1 ratio at 3 $\mu \mathrm{M}, 30 \mu \mathrm{M}$, and $90 \mu \mathrm{M}$ elicited dose-related calcium influx, with maximum influx at $90 \mu \mathrm{M}$. Capsaicin responses were dose-dependently diminished at $3 \mu \mathrm{M}, 30$ $\mu \mathrm{M}$, and $90 \mu \mathrm{M} \mathrm{CBG}+\mathrm{THC}+\mathrm{CBD}$ (Figure 2D), and Table 4. Pearson's coefficient $=-1.00$.

All three cannabinoids, CBG, CBD and THC - had dose-related inhibitory effects on capsaicin responses, whether applied separately or combined, with capsaicin responses distributed in a "U" shaped pattern (Figure 3). Maximum inhibition due to $\mathrm{CBG}$ alone was observed at 30 $\mu \mathrm{M}$, and that due to CBD and THC applied individually was observed at $100 \mu \mathrm{M}$. The combined inhibitory effect at $3 \mu \mathrm{M}$ was equivalent to the individual effects at $10 \mu \mathrm{M}$. Inhibition due to $30 \mu \mathrm{M}$ mix was equivalent to the individually applied cannabinoids at the same concentration. Inhibition due to $90 \mu \mathrm{M}$ mix was greater than that due to $100 \mu \mathrm{M} \mathrm{CBG}$ and $100 \mu \mathrm{M}$ THC, but similar to inhibition due to $100 \mu \mathrm{M}$ CBD (Figure 4). At higher concentrations, the inhibitory effects of $\mathrm{CBG}, \mathrm{CBD}$ and THC applied individually were diminished, ie, the capsaicin responses were greater, than those in the presence of lower cannabinoid concentrations. Inhibition due to $\mathrm{CBG}$ application diminished at the higher concentration of $100 \mu \mathrm{M}$. Similarly, inhibition due to THC was less at $150 \mu \mathrm{M}$ than at $100 \mu \mathrm{M}$.

The comparative inhibitory effects of the cannabinoids applied individually and combined, were distributed in an inverted U pattern, as shown in Figure 4. There was a high degree of correlation between cannabinoid-induced calcium influx and inhibition of capsaicin responses. Inhibition by $3 \mu \mathrm{M}$ combined application was significantly greater than by $1 \mu \mathrm{M} \mathrm{CBG}$ alone $(* \mathrm{P}<0.05)$, and equivalent to inhibition by individually applied cannabinoids at $10 \mu \mathrm{M}$. Inhibition by $30 \mu \mathrm{Mol}$ combined application was significantly greater than by $10 \mu \mathrm{M} C \mathrm{CBG}(* \mathrm{P}<0.05)$.

Table 2 Effect of THC

\begin{tabular}{|l|l|l|l|l|l|l|}
\hline THC concentration $(\mu \mathrm{M})$ & 0 & $\mathrm{I}$ & 10 & 30 & 100 & 150 \\
\hline $\begin{array}{l}\text { THC response } \\
\text { Mean } \pm \text { s.e.m }\end{array}$ & 0 & $24.2 \pm 7.9$ & $49.2 \pm 6.7$ & $61.4 \pm 4.2$ & $72.4 \pm 7.4$ & $50.7 \pm 15.8$ \\
\hline $\mathrm{N}$ (neurons) & $8(52)$ & $6(40)$ & $7(5 \mathrm{I})$ & $6(59)$ & $6(69)$ & $5(59)$ \\
\hline $\begin{array}{l}\text { Capsaicin response } \\
\text { Mean } \pm \text { s.e.m. }\end{array}$ & $100.0 \pm 20.5$ & $60.8 \pm 7.9$ & $43.3 \pm 10.4 *$ & $35.6 \pm 8.5^{*}$ & $24 \pm 5 * *$ & $45.5 \pm 11.2$ \\
\hline $\mathrm{N}$ (neurons) & $8(52)$ & $6(41)$ & $7(5 \mathrm{I})$ & $6(58)$ & $6(63)$ & $5(60)$ \\
\hline
\end{tabular}

Notes: Data showing dose related responses to $\Delta^{9} \mathrm{THC}$ application, and corresponding reduction of capsaicin responses. "N" indicates number of rats and the total number of neurons is in brackets. ${ }^{*} \mathrm{P}<0.05$, $* * \mathrm{P}<0.01$, Students $T$-Test. 
Table 3 Effect of CBD

\begin{tabular}{|l|l|l|l|l|l|}
\hline CBD concentration $(\mu \mathrm{M})$ & 0 & 1 & 10 & 30 & 100 \\
\hline $\begin{array}{l}\text { CBD response } \\
\text { Mean } \pm \text { s.e.m }\end{array}$ & 0 & $6.9 \pm 5.5$ & $45.6 \pm 10.6$ & $59.9 \pm 10.6$ & $74.3 \pm 2.8$ \\
\hline $\mathrm{N}$ (neurons) & $6(78)$ & $6(80)$ & $6(81)$ & $6(71)$ & $6(80)$ \\
\hline Capsaicin response Mean \pm s.e.m. & $100.0 \pm 4.7$ & $62.6 \pm 7 * *$ & $25 \pm 9.7 * * *$ & $18.6 \pm 7.1 * * *$ & $9.99 \pm 2.5 * * *$ \\
\hline $\mathrm{N}$ (neurons) & $6(78)$ & $6(80)$ & $6(81)$ & $6(71)$ & $6(80)$ \\
\hline
\end{tabular}

Notes: Data showing dose related responses to applied CBD, and reduction of capsaicin responses after CBD application. Pearson's coefficient $=-0.99$. "N" indicates number of rats and the total number of neurons is in brackets. **P $<0.01$, *** $\mathrm{P}<0.00 \mathrm{I}$, Students $T$-Test.

Table 4 Effect of Combined CBG+CBD+THC

\begin{tabular}{|l|l|l|l|l|}
\hline CBG + CBD + THC concentration $(\mu \mathrm{M})$ & 0 & 3 & 30 & 90 \\
\hline $\begin{array}{l}\text { CBG + CBD + THC response } \\
\text { Mean } \pm \text { s.e.m }\end{array}$ & 0 & $4.6 \pm 2.8$ & $40.3 \pm 4.3$ & $48 \pm 2.8$ \\
\hline $\mathrm{N}$ (neurons) & $8(52)$ & $6(47)$ & $6(57)$ & $6(55)$ \\
\hline $\begin{array}{l}\text { Capsaicin response } \\
\text { Mean } \pm \text { s.e.m. }\end{array}$ & $100.0 \pm 20.5$ & $44.4 \pm 7.5$ & $20.1 \pm 7.1^{* *}$ & $13.0 \pm 3.4 * *$ \\
\hline $\mathrm{N}$ (neurons) & $8(52)$ & $6(47)$ & $6(62)$ & $6(55)$ \\
\hline
\end{tabular}

Notes: Data showing dose related responses to combined CBG, CBD, and THC application, and corresponding reduction of capsaicin responses. Pearson's coefficient=-I.00. "N" indicates number of rats and the total number of neurons is in brackets. $* * P<0.01$, Students T-Test.

Inhibition by $90 \mu \mathrm{M}$ combined application was significantly greater than by $3 \mu \mathrm{M} \operatorname{mix}(* * \mathrm{P}<0.01), 30 \mu \mathrm{M}$ THC $(* \mathrm{P}<0.05)$, and by $100 \mu \mathrm{M} \mathrm{CBG}(* * * \mathrm{P}<0.001)$.

\section{Discussion}

This study aimed to determine the dose-related effects of the phytocannabinoids THC, CBG and CBD, applied individually and in combination, on capsaicin responses, using an in vitro model of neuronal hypersensitivity. ${ }^{33} \mathrm{CBD}$, $\mathrm{CBG}$ and THC induced calcium influx in a pattern characteristic of cannabinoids, resulting in desensitization to capsaicin stimulation. Capsaicin responses were inversely correlated with the magnitude of the cannabinoid response, with a high coefficient of correlation in each case, for CBG, THC, CBD and CBD/THC/CBG combination. This suggests that the cannabinoids activate DRG neurons resulting in desensitisation and consequent antinociception, in agreement with previous findings. ${ }^{26,27}$ These studies reported that $\mathrm{CBD}, \mathrm{CBG}$, cannabidivarin (CBDV), and tetrahydrocannabivarin (THCV) act as agonists that desensitize TRPV1 in human recombinant TRPV1 transfected HEK cells. Our study has further shown that the combined 1:1:1 mix of CBG:CBD:THC has the potential to enhance the potency of these compounds applied individually.

CBG showed a maximum effective concentration of $30 \mu \mathrm{M}$, with less efficacy at lower and higher concentrations. THC was most effective at $100 \mu \mathrm{M}$. The combined THC, CBD and CBG $(1: 1: 1)$ at $3 \mu \mathrm{M}$ was equivalent to $\mathrm{CBD}, \mathrm{CBG}$ or $\mathrm{THC}$ applied individually at $10 \mu \mathrm{M}$. Maximum inhibition by $90 \mu \mathrm{M}$ mix was similarly equivalent to inhibition by $100 \mu \mathrm{M} \mathrm{CBD}$ applied alone, and greater than that due to $\mathrm{CBG}$ and $\mathrm{THC}$ at $100 \mu \mathrm{M}$. This enhanced efficacy of combined phytocannabinoids is akin to the combined effects described for the endocannabinoids, ${ }^{17}$ and recently reviewed. ${ }^{39}$

While the cannabinoids caused neuronal activation, the calcium influx induced was less than that of the control (1 $\mu \mathrm{M}$ capsaicin). TRPV1 is expressed by nociceptive thin myelinated $\mathrm{A} \delta$ and unmyelinated $\mathrm{C}$ nerve fibres. It is activated by its highly specific potent stimulant capsaicin, ${ }^{40}$ resulting in the opening of cation-specific ion channels, with a high permeability to calcium. ${ }^{41}$ Calcium influx is known to activate the protein phosphatase calcineurin, that dephosphorylates TRPV1, causing its desensitization. $^{42}$ TRPV1 desensitization using high dose topical capsaicin is an effective treatment for neuropathic 
140

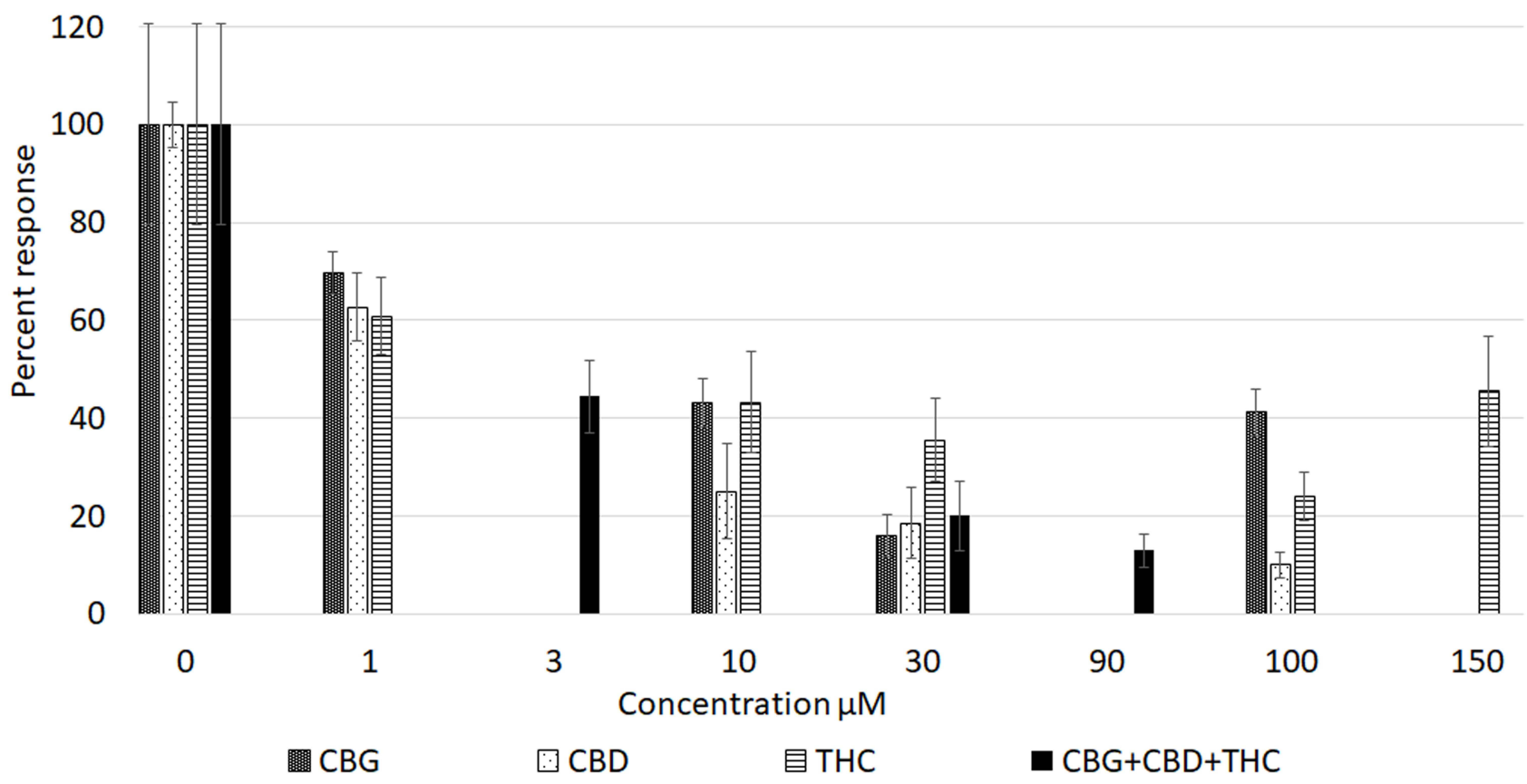

Figure 3 Graph showing comparison of dose-related reduction of capsaicin responses due to cannabinoids applied individually (patterned bars), or in combination (black bars).

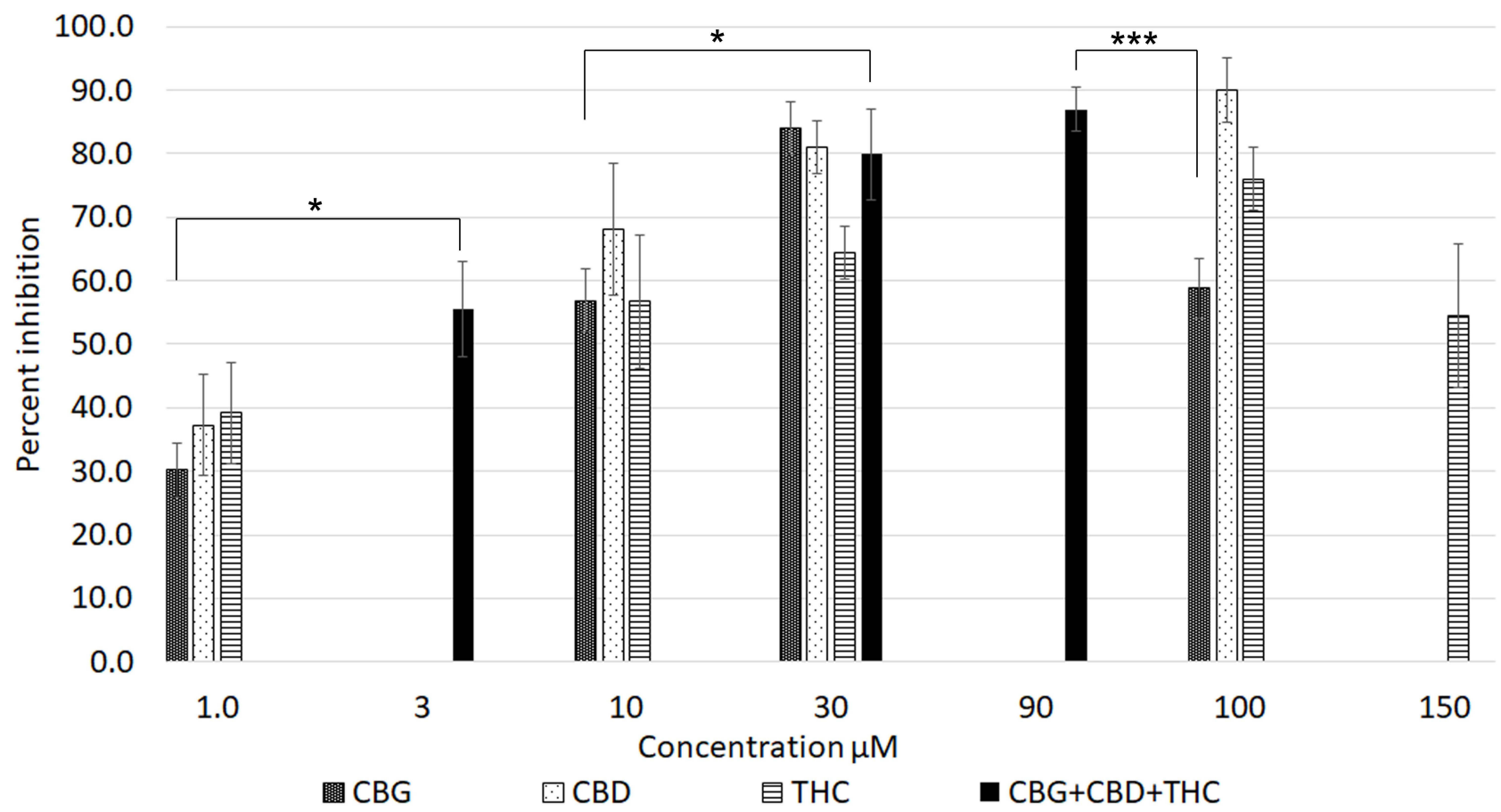

Figure 4 Graph showing the percentage inhibition of I $\mu$ M capsaicin responses in the presence of CBG, CBD and THC applied individually (patterned bars), and combined (black bars). $* \mathrm{P}<0.05$, $* * * \mathrm{P}<0.001$.

pain. ${ }^{43,44}$ We also observed reduced capsaicin responses in the presence of $1 \mu \mathrm{M} \mathrm{CBG}$, which did not elicit calcium influx, and significant desensitization at $1 \mu \mathrm{M} C B D$, suggesting that mechanisms involving different targets, are likely to be involved. Capsaicin application stimulates calcium influx, and blocks further capsaicin responses by 
desensitization. It is likely that cannabinoid mediated calcium influx has similar desensitizing effects to subsequent capsaicin stimuli. Investigating the mechanisms of action underlying TRPV1 desensitization by capsaicin and cannabinoids, and their differential effects, will be the focus of our future studies. These may enable optimal doses and formulations of cannabinoids for pain relief, such as specific combinations of cannabinoids taken orally, while minimising their individual side-effects. Elucidation of the pathways involved requires further investigations, including using receptor antagonists to identify their roles. As CBD activates TRPV1 at high concentration, other receptors involved in cannabinoid effects including $\mathrm{CB}_{1}$ and $\mathrm{CB}_{2}$ will require examination, using their respective antagonists. Interaction of cannabinoids with other receptors has recently been reviewed. ${ }^{39}$

The $\mathrm{CB}_{1}$ and $\mathrm{CB}_{2}$ receptors are $\mathrm{G}$ protein coupled receptors (GPCRs) that lead to adenylyl cyclase inhibition and decreased intracellular cAMP upon ligand binding. ${ }^{24}$ cAMP is a critical regulator of TRPV1 sensitivity, as TRPV1 is sensitized when phosphorylated, and desensitized when dephosphorylated. ${ }^{45,46}$ Thus, cannabinoid inhibition of capsaicin responses in our study may result from the activation of multiple targets. The mechanism(s) of cannabinoid desensitization may involve several receptors that are co-expressed in subsets of DRG neurons, and lead to their in vivo analgesic effects; these are considered in turn below for $\mathrm{CBG}, \mathrm{THC}, \mathrm{CBD}$ and their combination.

$\mathrm{CBG}$ has been shown to bind different receptors including TRPM8, ${ }^{27}$ TRPV1, ${ }^{27,47} \mathrm{CB}_{1}$ and $\mathrm{CB}_{2}{ }^{20,48}$ Experiments carried out in HEK-293 cells expressing the rat recombinant TRPM8 channel showed large decreases in response to the TRPM8 agonist icilin in the presence of increasing concentrations of $\mathrm{CBG}$, with maximum inhibition of icilin at a concentration of around $30 \mu \mathrm{M}$ CBG. Similar results were obtained in our study, utilising the TRPV1 agonist capsaicin instead of icilin. We found that $\mathrm{Ca}^{2+}$ influx in response to the addition of CBG was the highest at $30 \mu \mathrm{M}$, with a Pearson's coefficient value of -0.88 . This supports the proposition that $30 \mu \mathrm{M}$ is the most effective concentration of CBG for inhibiting calcium influx at both TPRM8 and TRPV1 channels. We attempted a study of higher CBG doses, eg, $150 \mu \mathrm{M}$; however, solubility issues of this viscous concentration were problematic.

Recent evidence using in vitro studies highlights many potential beneficial effects of CBG. These include treatment for neuroinflammation and oxidative stress, ${ }^{49}$ with reduced secretion of inflammatory mediators such as TNF- $\alpha$ and IL- $6 .{ }^{50}$ There is, however, very limited evidence that CBG has anti-nociceptive effects. Zagzoog et $\mathrm{al}^{48}$ used the in vivo Tetrad Test with multiple phytocannabinoids, including CBG, to determine their effects on spontaneous activity, catalepsy, hypothermia, and analgesia in mice, as defined by Ben Shabat et al. ${ }^{17}$ They found that CBG caused a small but statistically significant antinociceptive effect at $3 \mathrm{mg} / \mathrm{kg}$, as well as an anxiolytic effect at $10 \mathrm{mg} / \mathrm{kg}$. We have, in this study, provided in vitro evidence to support the anti-nociceptive effect of $\mathrm{CBG}$, reported in vivo previously.

In clinical trials of pain reduction with cannabis administration, adverse events were found to be more likely with high-THC preparations than multi-cannabinoid-containing products. ${ }^{51}$ Two randomised control trials ${ }^{52,53}$ found that inhaled cannabis provided significant analgesic effects in neuropathic pain, with increasing concentrations of THC providing greater pain relief. However, both studies reported that the higher THC concentrations were also associated with adverse cognitive side effects, such as memory deficits and impaired performance in neuropsychological tests. The psychoactive effect of THC is well established and limits the licensing of higher concentrations of THC in analgesic medicinal preparations.

It is because of these adverse effects that alternatives to high concentrations of THC are needed. Our study has shown that $\mathrm{THC}+\mathrm{CBD}+\mathrm{CBG}$ combined in a 1:1:1 proportion at $30 \mu \mathrm{M}$, was more effective than $100 \mu \mathrm{M}$ THC applied alone, and $30 \mu \mathrm{M} \mathrm{CBG}$ had an equivalent effect as the combined formulation at $30 \mu \mathrm{M}$. $30 \mu \mathrm{M} \mathrm{CBG}, 30$ $\mu \mathrm{M}$ and $90 \mu \mathrm{M} \mathrm{CBG}+\mathrm{CBD}+\mathrm{THC}$ combination is more effective at reducing capsaicin-induced calcium influx, than the most effective concentration of $100 \mu \mathrm{M}$ THC. By using a combination of $\mathrm{CBD}$, THC and CBG, equivalent or greater levels of analgesia could be achieved with lower concentrations of THC, thus minimising its sideeffects profile. The effects of cannabinoid combinations excluding THC have not been examined, and will be determined in our future studies. Such studies may guide the rational design of trials, to investigate their clinical efficacy and potential benefits.

A recent study, examining the effects of $\mathrm{CBD}$ on capsaicin response in rat DRG neurons, found that administration of $10 \mu \mathrm{M}$ and $50 \mu \mathrm{M}$ CBD caused significant calcium influx, but lower concentrations did not. ${ }^{36}$ In this study, $50 \mu \mathrm{M}$ CBD was the most effective concentration, in a similar range to $\mathrm{CBG}(30 \mu \mathrm{M})$. Various other receptor targets for CBD have been identified, such as the orphan 
G-protein coupled receptor GPR18, GPR55, PPARs, 5-HT1a and the $\alpha 3$ and $\alpha 1$ glycine receptors. ${ }^{54-57}$ A major difference in calcium influx mediated by cannabinoids and by capsaicin is their activation time-course. Capsaicin responses were very rapid (within a few seconds), while the cannabinoid responses were relatively delayed. The activation kinetics of cannabinoids require further investigation to explain this difference. As cannabinoids activate multiple targets, unlike capsaicin, their coexpression and interaction with TRPV1 requires further analysis. This would include use of specific receptor antagonists and elucidation of the signalling pathways involved. Ward et $\mathrm{al}^{58}$ researched the effects of CBD in mice with chemotherapy-induced hyperalgesia, and concluded that CBD successfully prevents the development of cold and mechanical allodynia. These results suggest that CBD could be used to prevent the development of chemotherapy-induced pain in humans. Further clinical investigations into the role of CBD-containing cannabinoid combinations for anti-nociception are also required.

Comelli et al ${ }^{59}$ used a rat model of neuropathic pain to demonstrate the anti-hyperalgesic effects of a cannabis extract containing multiple cannabinoid and noncannabinoid fractions. The plant extract, which included $\mathrm{CBD}$, THC and CBG, showed better efficacy than any cannabinoid administered individually. This data is supported by our findings that combined $\mathrm{CBD}+\mathrm{THC}+\mathrm{CBG}$ provides generally greater antinociceptive effects than THC applied alone, especially at $30 \mathrm{uM}$ concentration. Our study found that the most effective concentration of the combination was $90 \mu \mathrm{M} \mathrm{CBD}+\mathrm{THC}+\mathrm{CBG}$, which caused only $13 \%$ of the calcium influx in response to capsaicin as the control, and similar to inhibition by 100 $\mu \mathrm{M}$ CBD. Similarly, at $30 \mu \mathrm{M}$, there was no statistical difference between the $\mathrm{CBD}+\mathrm{THC}+\mathrm{CBG}$ combination treatment and $\mathrm{CBG}$ alone. Higher concentration of the $\mathrm{CBD}+\mathrm{THC}+\mathrm{CBG}$ combination treatment than $90 \mu \mathrm{M}$ could not be used in this study due to limitations in solubility of the stock solutions.

A four-way crossover clinical trial randomised patients with chronic fibromyalgia pain to different ratios of inhaled THC and CBD (high THC, roughly 1:1 THC:CBD and high CBD or placebo). ${ }^{60}$ Only those receiving the THC/CBD combination treatment had a significant improvement of pain compared to placebo. This trial also found that CBD increased plasma THC concentrations, but decreased THCinduced analgesic effects, highlighting the complex pharmacokinetic and pharmacodynamic interactions of cannabinoids.
In conclusion, this study has determined that the cannabinoids $\mathrm{CBG}, \mathrm{CBD}$ and THC dose-dependently reduce capsaicin responses in rat DRG neurons, in a model of neuronal hypersensitivity. The combined treatment has the potential to enhance the potency of individually applied cannabinoids. The cannabinoids dose-dependently caused calcium influx, which was inversely correlated to subsequent capsaicin response. These results highlight the potential anti-nociceptive application of phytocannabinoids, particularly in combination.

\section{Acknowledgment}

This study was funded by EMMAC Life Sciences, UK.

\section{Author Contributions}

All authors contributed to data analysis, drafting or revising the article, gave final approval of the version to be published, agreed to the submitted journal, and agree to be accountable for all aspects of the work.

\section{Disclosure}

This study was funded by EMMAC Life Sciences Ltd. Barbara Pacchetti and Mikael H Sodergren are employees of EMMAC Life Sciences Ltd. Barbara Pacchetti reports personal fees from EMMAC Life Sciences, outside the submitted work. Mikael H Sodergren reports consultancy for and personal fees from Emmac Life Sciences, outside the submitted work. The authors have no other relevant affiliations or financial involvement with any organization or entity with a financial interest in or financial conflict with the subject matter or materials discussed in the manuscript apart from those disclosed and report no other potential conflicts of interest for this work. No writing assistance was utilized in the production of this manuscript.

\section{References}

1. Merskey H, Bogduk N, editors, IASP Task Force on Taxonomy, Part III: Pain Terms, a Current List with Definitions and Notes on Usage. Seattle, WA: IASP Press; 1994:209-214.

2. Fayaz A, Croft P, Langford R, Donaldson J, Jones G. Prevalence of chronic pain in the UK: a systematic review and meta-analysis of population studies. BMJ Open. 2016;6(6):e010364. doi:10.1136/bmjopen-2015-010364

3. Fletcher D, Stamer UM, Pogatzki-Zahn E. Chronic postsurgical pain in Europe: an observational study. Eur J Anaesthesiol. 2015;32:725-734. doi:10.1097/EJA.0000000000000319

4. Mills SEE, Nicholson KP, Smith BH. (2019) Chronic pain: a review of its epidemiology and associated factors in population-based studies. $\mathrm{Br}$ $J$ Anaesth. 2019;123(2):e273-e283. doi:10.1016/j.bja.2019.03.023 
5. Anand U. Mechanisms and management of cancer pain. Alison E, editor. The Cancer Handbook; Copyright (C) 2005 John Wiley \& Sons, Ltd. Chapter 310; 2005.

6. Gaoni Y, Mechoulam R. Isolation, structure, and partial synthesis of an active constituent of hashish. $J$ Am Chem Soc. 1964;1 (86):1646-1647.

7. Pertwee RG. The pharmacology and therapeutic potential of cannabidiol. In: Di Marzo V, editor. Cannabinoids. NY, USA: Kluwer Academic/Plenum Publishers; 2004:32-83.

8. Wendelmuth C, Wirz S, Torontali M, Gastmeier A, Gastmeier K. Dronabinol bei geriatrischen Schmerz- und Palliativpatienten. Eine retrospektive Auswertung der ambulanten kassenärztlichen Therapie [Dronabinol in geriatric pain and palliative care patients: a retrospective evaluation of statutory-health-insurance-covered outpatient medical treatment]. Schmerz. 2019;33(5):384-391. doi:10.1007/s00482-019-00408-1. [German].

9. Calhoun SR, Galloway GP, Smith DE. Abuse potential of dronabinol. (Marinol). J Psychoactive Drugs. 1998;30:187-196. doi:10.1080/ 02791072.1998.10399689

10. Clermont-Gnamien S, Atlani S, Attal N, Le Mercier F, Guirimand F, Brasseur L. Utilisation thérapeutique du D9-tétrahydrocannabinol (dronabinol) dans les douleurs neuropathiques réfractaires [The therapeutic use of D9-tetrahydrocannabinol (dronabinol) in refractory neuropathic pain]. Presse Med. 2002;31(39 Pt 1):1840-1845. French.

11. Attal N, Brasseur L, Guirimand D, Clermond-Gnamien S, Atlami S, Bouhassira D. Are oral cannabinoids safe and effective in refractory neuropathic pain? Eur J Pain. 2004;8(2):173-177. doi:10.1016/ S1090-3801(03)00084-3

12. Russo EB. Cannabinoids in the management of difficult to treat pain. Ther Clin Risk Manag. 2008;4(1):245-259. doi:10.2147/TCRM. $\mathrm{S} 1928$

13. Holdcroft A, Maze M. Dor'e C Tebbs S, Thompson S. A multicenter dose-escalation study of the analgesic and adverse effects of an oral cannabis extract (Cannador) for postoperative pain management. Anesthesiology. 2006;104(5):1040-1046. doi:10.1097/00000542200605000-00021

14. Berman JS, Symonds C, Birch R. Efficacy of two cannabis based medicinal extracts for relief of central neuropathic pain from brachial plexus avulsion: results of a randomised controlled trial. Pain. 2004;112(3):299-306. doi:10.1016/j.pain.2004.09.013

15. Langford RM, Mares J, Novotna A, et al. A double-blind, randomized, placebo-controlled, parallel-group study of THC/CBD oromucosal spray in combination with the existing treatment regimen, in the relief of central neuropathic pain in patients with multiple sclerosis. J Neurol. 2013;260(4):984-997. doi:10.1007/s00415-012-6739-4

16. Russo EB. Taming THC: potential cannabis synergy and phytocannabinoid-terpenoid entourage effects. BrJ Pharmacol. 2011;(2011)(163):1344-1364. doi:10.1111/j.1476-5381.2011.01238.x

17. Ben-Shabat S, Fride E, Sheskin T, et al. An entourage effect: inactive endogenous fatty acid glycerol esters enhance 2-arachidonoylglycerol cannabinoid activity. Eur J Pharmacol. 1998;353(1):23-31. doi:10.1016/S0014-2999(98)00392-6

18. Mlost J, Bryk M, Starowicz K. Cannabidiol for Pain treatment: focus on pharmacology and mechanism of action. Int J Mol Sci. 2020;21 (22):8870. doi:10.3390/ijms21228870

19. Karniol I, Carlini E. Pharmacological interaction between cannabidiol and 9-tetrahydrocannabinol. Psychopharmacologia. 1973;33 (1):53-70. doi:10.1007/BF00428793

20. Navarro G, Varani K, Reyes-Resina I. Sánchez de Medina V, et al. Cannabigerol action at Cannabinoid $\mathrm{CB} 1$ and $\mathrm{CB} 2$ receptors and at CB1-CB2 heteroreceptor complexes. Front Pharmacol. 2018;9:632. doi:10.3389/fphar.2018.00632

21. Evans FJ. Cannabinoids: the separation of central from peripheral effects on a structural basis. Planta Med. 1991;57:S60-7. doi:10.1055/s-2006-960231
22. Devane WA, Dysarz Ill FA, Johnson MR, Melvin LS, Howlett AC. Determination and characterization of a cannabinoid receptor in rat brain. Mol Pharmacol. 1988;34:605-613.

23. Munro S, Thomas KL, Abu-Shaar M. Molecular characterization of a peripheral receptor for cannabinoids. Nature. 1993;365 (6441):61-65. doi:10.1038/365061a0

24. Howlett AC, Johnson MR, Melvin LS, Milne GM. Nonclassical cannabinoid analgetics inhibit adenylate cyclase: development of a cannabinoid receptor model. Mol Pharmacol. 1988;33:297-302.

25. Bisogno T, Hanus L, De Petrocellis L, et al. Molecular targets for cannabidiol and its synthetic analogues: effect on vanilloid VR1 receptors and on the cellular uptake and enzymatic hydrolysis of anandamide. Br J Pharmacol. 2001;134:845-852. doi:10.1038/sj. bjp. 0704327

26. Iannotti FA, Hill CL, Leo A, Alhuseini A, Soubrane C, Mazzarella E. Nonpsychotropic plant cannabinoids, cannabidivarin (CBDV) and cannabidiol (CBD), activate and desensitize transient receptor potential vanilloid 1 (TRPV1) channels in vitro: potential for the treatment of neuronal hyperexcitability. ACS Chem Neurosci. 2014;5 (11):1131-1141. doi:10.1021/cn5000524

27. De Petrocellis L, Ligresti A, Moriello AS, et al. Effects of cannabinoids and cannabinoid-enriched cannabis extracts on TRP channels and endocannabinoid metabolic enzymes. Br J Pharmacol. 2011;163 (7):1479-1494. doi:10.1111/j.1476-5381.2010.01166.x

28. Caterina MJ, Schumacher MA, Tominaga M, Rosen TA, Levine J, Julius D. The capsaicin receptor: a heat-activated ion channel in the pain pathway. Nature. 1997;389:816-824. doi:10.1038/39807

29. Davis JB, Gray J, Gunthorpe MJ, et al. Vanilloid receptor-1 is essential for inflammatory thermal hyperalgesia. Nature. 2000;405:183-187. doi:10.1038/35012076

30. Richardson JD, Kilo S, Hargreaves KM. Cannabinoids reduce hyperalgesia and inflammation via interaction with peripheral $\mathrm{CB} 1$ receptors. Pain. 1998;75(1):111-119. doi:10.1016/S0304-3959(97)00213-3

31. Jordt SE, Bautista DM, Chuang H, et al. Mustard oils and cannabinoids excite sensory nerve fibres through the TRP channel ANKTM1. Nature. 2004;427:260-265. doi:10.1038/nature02282

32. Patapoutian A, Peier SM, Story GM, Viswanath V. ThermoTRP channels and beyond: mechanisms of temperature sensation. Nat Rev Neurosci. 2003;4:529-539. doi:10.1038/nrn1141

33. Anand U, Otto WR, Casula MA, et al. The effect of neurotrophic factors on morphology TRPV1 expression and capsaicin responses of cultured human DRG sensory neurons, Neurosci. Lett. 2006;399:51-56.

34. Anand U, Otto WR, Facer P, et al. TRPA1 receptor localisation in the human peripheral nervous system and functional studies in cultured human and rat DRG neurons. Neurosci Lett. 2008;438:221-227. doi:10.1016/j.neulet.2008.04.007

35. Akopian AN, Ruparel NB, Patwardhan A, Hargreaves KM. Cannabinoids desensitize capsaicin and mustard oil responses in sensory neurons via TRPA1 activation. $J$ Neurosci. 2008;28 (5):1064-1075. doi:10.1523/JNEUROSCI.1565-06.2008

36. Anand U, Jones B, Korchev Y, et al. CBD effects on TRPV1 signaling pathways in cultured DRG neurons. J Pain Res. 2020;11 (13):2269-2278. doi:10.2147/JPR.S258433

37. Anand P. Neurotrophic factors and their receptors in human sensory neuropathies. Prog Brain Res. 2004;146:477-492.36.

38. Bar KJ, Saldanha GJ, Kennedy AJ, et al. GDNF and its receptor component Ret in injured human nerves and dorsal root ganglia. Neuroreport. 1998;9(1):43-47. doi:10.1097/00001756-199801050-00009

39. Anand U, Pacchetti B. Anand P and Sodergren MH. Cannabis-based medicines and pain: a review of potential synergistic and entourage effects. Pain Manag. 2021;11(4):395-403. doi:10.2217/pmt-2020-0110

40. Holzer P. Capsaicin: cellular targets, mechanisms of action, and selectivity for thin sensory neurons. Pharmacol Rev. 1991;43:143-20143. 
41. Wood JN, Winter J, James IF, Rang HP, Yeats JC, Bevan S. Capsaicin-induced ion fluxes in dorsal root ganglion cells in culture. J Neurosci. 1988;8:3208-3220.

42. Docherty RJ, Yeats JC, Bevan S, Bodekke HW. Inhibition of calcineurin inhibits the desensitization of capsaicin-evoked currents in cultured dorsal root ganglion neurones from adult rats. Pflugers Arch. 1996;431(6):828-837. doi:10.1007/s004240050074

43. Anand P, Bley K. Topical capsaicin for pain management: therapeutic potential and mechanisms of action of the new high-concentration capsaicin 8\% patch. Br J Anaesth. 2011;(2011(107):490-502. doi:10.1093/bja/aer260

44. Sousa-Valente J, Andreou AP, Urban L, Nagy I. Transient receptor potential ion channels in primary sensory neurons as targets for novel analgesics. Br J Pharmacol. 2014;171(10):2508-2527. doi:10.1111/ bph.12532

45. Bhave G, Zhu W, Wang H, Brasier DJ, Oxford GS, Gereau RW. cAMP-dependent protein kinase regulates desensitization of the capsaicin receptor (VR1) by direct phosphorylation. Neuron. 2002;35:721-731. doi:10.1016/S0896-6273(02)00802-4

46. Mohapatra DP, Nau C. Desensitization of capsaicin-activated currents in the vanilloid receptor TRPV1 is decreased by the cyclic AMP-dependent protein kinase pathway. $J$ Biol Chem. 2003;278:50080-50090. doi:10.1074/jbc.M306619200

47. Starkus J, Jansen C, Shimoda LMN, Stokes AJ, Small-Howard AL, Turner H. Diverse TRPV1 responses to cannabinoids. Channels. 2019;13(1):172-191. doi:10.1080/19336950.2019.1619436

48. Zagzoog A, Mohamed KA, Kim HJJ, et al. In vitro and in vivo pharmacological activity of minor cannabinoids isolated from Cannabis sativa. Cannabis Sativa Sci Rep. 2020;10(1):20405. doi:10.1038/s41598-020-77175-y

49. Gugliandolo A, Pollastro F, Grassi G, Bramanti P, Mazzon E. In vitro model of neuroinflammation: efficacy of cannabigerol, a non-psychoactive cannabinoid. Int J Mol Sci. 2018;19(7):1992. doi:10.3390/ijms 19071992

50. Granja A, Carrillo-Salinas F, Pagani A, et al. A Cannabigerol quinone alleviates neuroinflammation in a chronic model of multiple sclerosis. J Neuroimmune Pharmacol. 2012;7(4):1002-1016. doi:10.1007/ s11481-012-9399-3

51. Haleem R, Wright R, Scoping A. Review on clinical trials of pain reduction with cannabis administration in adults. $J$ Clin Med Res. 2020;12(6):344-351. doi:10.14740/jocmr4210
52. Wilsey B, Marcotte T, Tsodikov A, et al. A randomized, placebo-controlled, crossover trial of cannabis cigarettes in neuropathic pain. J Pain. 2008;9(6):506-521. doi:10.1016/j. jpain.2007.12.010

53. Wallace MS, Marcotte TD, Umlauf A, Gouaux B, Atkinson JH. Efficacy of inhaled cannabis on painful diabetic neuropathy. J Pain. 2015;16(7):616-627. doi:10.1016/j.jpain.2015.03.008

54. Okine BN, Gaspar JC, Finn DP. PPARs and pain. Br J Pharmacol. 2018;176(10):1421-1442. doi:10.1111/bph.14339

55. Costa B, Giagnoni G, Franke C, Trovato EA, Colleoni M. Vanilloid TRPV1 receptor mediates the antihyperalgesic effect of the nonpsychoactive cannabinoid, cannabidiol, in a rat model of acute inflammation. Br J Pharmacol. 2004;143:247-250. doi:10.1038/sj. bjp.0705920

56. Patwardhan AM, Jeske NA, Price TJ, Gamper N, Akopian AN, Hargreaves KM. The cannabinoid WIN 55212-2 inhibits transient receptor potential vanilloid 1 (TRPV1) and evokes peripheral antihyperalgesia via calcineurin. Proc Natl Acad Sci. 2006;103 (30):11393-11398. doi:10.1073/pnas.0603861103

57. Lowin T, Schneider M, Pongratz G. Joints for joints: cannabinoids in the treatment of rheumatoid arthritis. Curr Opin Rheumatol. 2019;31:271-278. doi:10.1097/BOR.0000000000000590

58. Ward SJ, Ramirez MD, Neelakantan H, Walker EA. Cannabidiol prevents the development of cold and mechanical allodynia in paclitaxel-treated female C57B16 mice. Anaesth Analgesia. 2011;113(4):947-950. doi:10.1213/ANE.0b013e3182283486

59. Comelli F, Giagnoni G, Bettoni I, Colleoni M, Costa B. Antihyperalgesic effect of a Cannabis sativa extract in a rat model of neuropathic pain: mechanisms involved. Phytotherapy Res. 2008;22(8):1017-1024. doi:10.1002/ptr.2401

60. van de Donk T, Niesters M, Kowal MA, Olofsen E, Dahan A, van Velzen M. An experimental randomized study on the analgesic effects of pharmaceutical-grade cannabis in chronic pain patients with fibromyalgia. Pain. 2019;160(4):860-869. doi:10.1097/j. pain.0000000000001464
Journal of Pain Research

\section{Publish your work in this journal}

The Journal of Pain Research is an international, peer reviewed, open access, online journal that welcomes laboratory and clinical findings in the fields of pain research and the prevention and management of pain. Original research, reviews, symposium reports, hypothesis formation and commentaries are all considered for publication. The manuscript management system is completely online and includes a very quick and fair peer-review system, which is all easy to use. Visit http:// www.dovepress.com/testimonials.php to read real quotes from published authors. 